\title{
UK Renal Registry 14th Annual Report: Chapter 11 Clinical, Haematological and Biochemical Parameters in Patients receiving Renal Replacement Therapy in Paediatric Centres in the UK in 2010: National and Centre-Specific Analyses
}

\author{
Rishi Pruthi ${ }^{a}$, Heather Maxwell ${ }^{b}$, Anna Casula ${ }^{a}$, Yincent Tse ${ }^{c}$, Manish D Sinha ${ }^{d}$, \\ Catherine O'Brien ${ }^{\mathrm{e}}$, Malcolm Lewis ${ }^{\mathrm{f}}$, Carol Inward ${ }^{\mathrm{g}}$ \\ aUK Renal Registry, Bristol, UK; ${ }^{b}$ Royal Hospital for Sick Children (Yorkhill), Glasgow, UK; 'Royal Victoria Infirmary,

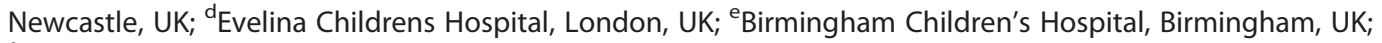 \\ ${ }^{\mathrm{f}}$ Manchester Children's Hospital, Manchester, UK; ${ }^{9}$ Bristol Royal Hospital for Children, Bristol, UK
}

\section{Key Words}

Biochemical variables - Children - Dialysis - ERF - Haemoglobin · Height · Quality improvement · Transplant · Weight

\begin{abstract}
Background: The British Association for Paediatric Nephrology Registry was established to analyse data related to renal replacement therapy (RRT) for children. The registry receives data from the 13 paediatric nephrology centres in the UK. Aim: To provide centre specific data so that individual centres can reflect on the contribution that their data makes to the national picture and to determine the extent to which their patient parameters meet nationally agreed audit standards for the management of children with established renal failure. Method: Data returns have been a mixture of electronic and paper returns. Data were analysed to calculate summary statistics and where applicable the percentage achieving an audit standard. The standards used were those set out by the Renal Association
\end{abstract}

and the National Institute for Health and Clinical Excellence. Results: Anthropometric data confirmed that children receiving RRT are short compared to healthy peers. Amongst patients with a height $z$-score of $<2 \mathrm{SD}$ between 2000 and 2010, 27\% were receiving growth hormone if they were on dialysis compared to $10 \%$ if they had a functioning transplant. Blood pressure was higher in children receiving RRT than in healthy children with wide inter-centre variation. The percentage of patients achieving the treatment standards for haemoglobin and ferritin has gradually increased over the last decade, more noticeably in dialysis patients. Analysis by age showed that the proportion of children with a haemoglobin below the standard was greatest for the under 5 years age group irrespective of RRT modality. The control of renal bone disease remained challenging. Conclusions: Optimizing growth in children on RRT remains challenging and the control of bone biochemistry in children on dialysis is imperfect. However there is some room for optimism as this year's data shows an improving trend in the control of anaemia and systolic blood pressure.

\section{KARGER \\ Fax +4161306 1234 E-Mail karger@karger.ch} www.karger.com
C 2011 S. Karger AG, Basel

$1160-2110 / 12 / 1205-0219 \$ 38.00 / 0$

Accessible online at: www.karger.com/nec
Carol Inward

UK Renal Registry, Southmead Hospital, Southmead Road, Bristol, BS10 5NB, UK

Email: renalregistry@renalregistry.nhs.uk 


\section{Introduction}

The British Association for Paediatric Nephrology (BAPN) Registry was established in 1996 in parallel with the establishment of the UK Renal Registry (UKRR). The data to be collected was agreed by the registry committee of the BAPN and data collection forms distributed to each of the participating centres. Data returns have been a mixture of electronic and paper returns. Progress has been made towards a merger of the adult and paediatric registries with increasing electronic paediatric returns coming from hospital renal information systems. When complete this will allow more detailed analysis of laboratory parameters. Currently, only one annual dataset is recorded for each patient.

This year the report focuses on the following variables for the prevalent paediatric dialysis and transplantation cohort on 31st December 2010:

1. Report on the completeness of data returns to the renal registry

2. Overview of anthropometric characteristics in children with established renal failure (ERF)

3. Overview of blood pressure control in children with ERF

4. Overview of anaemia control in children with ERF

5. Key biochemical findings in this population

Analyses of prevalent paediatric patients receiving renal replacement therapy for the year 2010 and for the period 2000 to 2010 inclusive are reported. Due to low numbers of patients in each cohort no incident cohort analyses have been undertaken. Centre specific data for each paediatric nephrology centre in the UK has also been provided.

\section{Methods}

There were 13 centres providing care for children requiring renal replacement therapy in the UK, ten of which also provided surgical renal transplant services. All 13 centres provide outpatient and in-patient follow up for children who have received kidney transplants. Centres are listed in table 11.1 and appendix K. This year a significant amount of effort has been put into improving the overall accuracy of the entire paediatric dataset by clinical teams, data managers and statisticians (see chapter 5 Demography of the UK Paediatric RRT population).

\section{Data collection}

The data presented in this report relate to the annual census date of 31st December 2010.
Table 11.1. Paediatric renal centres, their abbreviations and IT systems

\begin{tabular}{|c|c|c|}
\hline Paediatric centre & Abbreviation & $\begin{array}{c}\text { Renal } \\
\text { IT system }\end{array}$ \\
\hline Belfast & Blfst_P & Mediqal $^{\mathrm{a}}$ \\
\hline Birmingham & Bham_P & Proton \\
\hline Bristol & Brstl_P & Proton \\
\hline Cardiff & Cardf_P & Proton \\
\hline Glasgow & Glasg_P & Filemaker \\
\hline Leeds & Leeds_P & Proton \\
\hline Liverpool & Livpl_P & None \\
\hline London Evelina & L Eve_P & Proton ${ }^{\mathrm{b}}$ \\
\hline London Great Ormond Street & L GOSH_P & Proton $^{\mathrm{b}}$ \\
\hline Manchester & Manch_P & None \\
\hline Newcastle & Newc_P & $\begin{array}{l}\text { Clinical } \\
\text { Vision }^{a}\end{array}$ \\
\hline Nottingham & Nottm_P & Proton \\
\hline Southampton & Soton_P & Bespoke $^{c}$ \\
\hline
\end{tabular}

${ }^{a}$ Installed, although paper data submissions received in 2010

${ }^{\mathrm{b}} \mathrm{GOSH}$ and London Evelina have a link to the PROTON system in Bristol but with no lab links

${ }^{c}$ Recent implementation of a bespoke renal IT system has enabled transmission of a limited dataset from Southampton this year

Those paediatric centres with access to renal IT systems submitted encrypted electronic data directly to the UKRR. Those centres without access sent paper or electronic returns in the original BAPN database format which were then entered into the original BAPN database as in previous years. Complete transfer to the UKRR encrypted database is still awaited.

Governance, reporting and standardisation

Information governance, reporting and standardisation were all performed in an identical manner to previous analyses to allow comparison [1]. With the value of many clinical parameters in childhood varying with age and size, data are presented as z-scores.

\section{Anthropometry}

The reference range for height $(\mathrm{Ht})$, weight $(\mathrm{Wt})$ and body mass index (BMI) in childhood varies with gender and age. BMI was calculated using the formula BMI $=\mathrm{Wt}(\mathrm{kg}) / \mathrm{Ht}(\mathrm{m})^{2}$. Height, weight and BMI were all adjusted for age and z-scores were calculated based on the British 1990 reference data for height and weight [2].

\section{Blood pressure (BP)}

The reference range for blood pressure varies with gender, age and height. The data is therefore presented as z-scores based on data from the fourth report of the National High Blood Pressure Education Programme (NHBPEP) working group in the United States [3].

\section{Laboratory values}

Haemoglobin $(\mathrm{Hb})$, ferritin (Ferr), calcium $(\mathrm{Ca})$ and phosphate (Phos) were analysed using age related laboratory reference ranges as in table 11.2. Data analysis is presented for each centre individually and at a national level for each variable. 
Table 11.2 Summary of relevant biochemical clinical audit measures

\begin{tabular}{|c|c|c|c|c|}
\hline \multirow[b]{2}{*}{ Parameter } & \multicolumn{4}{|c|}{ Age } \\
\hline & $<1$ year & $1-5$ years & $6-12$ years & $>12$ years \\
\hline $\begin{array}{l}\text { Haemoglobin }(\mathrm{g} / \mathrm{dl}) \text { (NICE guidelines for } \\
\text { dialysis patients only) }\end{array}$ & $\begin{array}{l}<10.0 \text { for }<2 y r \\
\text { Maintain } 10-12 \\
\text { for }<2 \mathrm{yr}\end{array}$ & $\begin{array}{c}<11.0 \text { for }>2 \mathrm{yr} \\
\text { Maintain } 10.5-12.5 \\
\quad \text { for }>2 \mathrm{yr}\end{array}$ & $\begin{array}{c}<11.0 \text { for }>2 \mathrm{yr} \\
\text { Maintain } 10.5-12.5 \\
\text { for }>2 \mathrm{yr}\end{array}$ & $\begin{array}{c}<11.0 \text { for }>2 \mathrm{yr} \\
\text { Maintain } 10.5-12.5 \\
\text { for }>2 \mathrm{yr}\end{array}$ \\
\hline Ferritin $(\mathrm{g} / \mathrm{L})$ & $200-500$ & $200-500$ & $200-500$ & $200-500$ \\
\hline Corrected calcium (mmol/L) & $2.24-2.74$ & $2.19-2.69$ & $2.19-2.69$ & $2.15-2.55$ \\
\hline Phosphate (mmol/L) & $1.1-1.95$ & $1.05-1.75$ & $1.05-1.75$ & $1.05-1.75$ \\
\hline eGFR (transplant patients) & \multicolumn{4}{|c|}{$\begin{array}{l}\text { Estimated GFR (eGFR) as per Schwartz formula: (height } \times \mathrm{k} \text { )/ plasma creatinine } \\
\text { The value for } \mathrm{k} \text { is that in use at the reporting renal centre }\end{array}$} \\
\hline
\end{tabular}

\section{Statistical analysis}

Data were analysed to calculate summary statistics (maximum, minimum, mean and median values in addition to standard deviation and quartile ranges). Where applicable, the percentage achieving the audit standard was also calculated. If a patient had missing data, they were excluded from the relevant analyses.

Longitudinal analyses of attainment of standards over time were also performed. This was based on a single data point per ERF patient per year collected as described previously. Changing audit standards over time and variable data return for previous years encourages cautious interpretation of these analyses. All analyses were done using SAS 9.2.

\section{Standards}

Standards are from the treatment of adults and children with renal failure, Renal Association 2002 guidelines unless otherwise stated [4].

\section{Anthropometry}

'Height and weight should be monitored at each clinic visit. Measures of supine length or standing head circumference should be measured during each visit up to two years of age and 6 monthly up to 5 years of age. All measurements should be plotted on European reference growth charts for healthy children.'

\section{Blood Pressure}

'Blood pressure varies throughout childhood and should be maintained within 2 standard deviations of the mean for normal children of the same height and sex. Systolic blood pressure during PD or post-HD should be maintained at <90th percentile for age, gender and height.'

The analyses of blood pressure in this report present the achievement of blood pressures at or below the 90th percentiles.

\section{Anaemia}

Guidance on the management of anaemia in adults and children with chronic kidney disease was published by the National Institute for Clinical Excellence (NICE) in 2006 (Clinical Guideline 39) [5]. The recommendation in this guidance is that in children with chronic kidney disease, treatment should maintain stable haemoglobin levels between 10 and $12 \mathrm{~g} / \mathrm{dl}$ in children below 2 years of age and between 10.5 and $12.5 \mathrm{~g} / \mathrm{dl}$ in children above 2 years of age. For the purposes of this report, the NICE standards have been adopted.

\section{Calcium, phosphate and parathyroid hormone}

levels

Phosphate and calcium should be kept within the normal range [4]. For analyses of calcium and phosphate the age related ranges as described previously have been used [1]. 


\section{Results}

\section{Data completeness}

Tables 11.3 to 11.6 show the completeness of data returns for transplant and dialysis patients for 2010 and the 2000-2010 period. Each patient was assessed with regard to the completeness of data for each year between 2000 and 2010. Thus the total does not represent the number of patients treated but the number of patient treatment years assessed for each modality.

In 2010, overall completeness was good, with GOSH showing a significant improvement in data returns for height, weight and blood pressure compared to the 2009 report. Data completeness for bicarbonate was low in dialysis patients (59.3\%) in 2010 partly as a result of data extraction difficulties which are being addressed.

In 2010, Southampton, Newcastle and Manchester were only able to provide a limited dataset due to a combination of technical difficulties and limited resources resulting in their respective low completion percentages. The original BAPN dataset did not include details about bone metabolism for transplanted patients. This explains the poor returns in this area for centres without automatic electronic download of these items from their laboratories into a renal data system.

Height, weight and BMI

Figures 11.1 and 11.4 show that children receiving renal replacement therapy were short for their age, the height deficit being greater in children on dialysis than in those who had a functioning kidney transplant. The overall median $\mathrm{z}$-score was -1.26 in the transplanted group and -1.80 in the dialysis group.

Children with a functioning kidney transplant had a normal weight (median z-score of -0.02), (figure 11.2), whilst those on dialysis had a weight below that of healthy children with a median $\mathrm{z}$-score of -0.96 (figure 11.5).

Body mass index in children with a functioning transplant in 2010 showed inter-centre variation with a median $\mathrm{z}$-score of 0.85 (figure 11.3). The median BMI $z$-score in those on dialysis was lower at 0.30 (figure 11.6). This data indicates that in the group as a whole, children on dialysis have an appropriate weight for height with a BMI z-score close to zero.

Figure 11.7 shows that the UK average median $\mathrm{z}$-score for height in children on renal replacement therapy and the percentage of children receiving growth hormone each year did not change between 2000 and 2010. Amongst those patients with a height $\mathrm{z}$-score of $<2$ SD between 2000 and 2010,27\% were noted to be receiving growth hormone if they were on dialysis, compared to only $10 \%$ if they had a functioning transplant. More detailed analysis including primary diagnosis and comorbidity will be required to establish the factors contributing to this.

\section{Blood pressure}

Analyses of blood pressure management have shown that blood pressure is higher in children receiving renal

Table 11.3. Percentage data completeness for transplant patients by centre for each variable and total number of patients per centre in 2010

\begin{tabular}{|c|c|c|c|c|c|c|c|c|c|c|c|c|c|c|c|}
\hline Centre & $\begin{array}{c}\text { Transplant } \\
\text { patients } \\
\mathrm{N}\end{array}$ & Height & Weight & BMI & $\begin{array}{c}\text { Systolic } \\
\text { BP }\end{array}$ & $\mathrm{Hb}$ & Creat & Ferr & $\mathrm{EPO}$ & $\begin{array}{l}\text { IV } \\
\text { iron }\end{array}$ & Chol & $\mathrm{HCO}_{3}$ & eGFR & $\mathrm{Ca}$ & Phos \\
\hline Blfst_P & 22 & 90.9 & 90.9 & 90.9 & 90.9 & 90.9 & 90.9 & 18.2 & 77.3 & 72.7 & 63.6 & 81.8 & 90.9 & 0.0 & 0.0 \\
\hline Bham_P & 55 & 98.2 & 98.2 & 98.2 & 98.2 & 98.2 & 98.2 & 54.5 & 98.2 & 98.2 & 69.1 & 98.2 & 98.2 & 98.2 & 98.2 \\
\hline Brstl_P & 36 & 91.7 & 94.4 & 91.7 & 91.7 & 94.4 & 94.4 & 52.8 & 94.4 & 94.4 & 72.2 & 91.7 & 91.7 & 88.9 & 91.7 \\
\hline Cardf_P & 13 & 100.0 & 100.0 & 100.0 & 100.0 & 100.0 & 100.0 & 76.9 & 23.1 & 7.7 & 53.8 & 100.0 & 100.0 & 100.0 & 100.0 \\
\hline Glasg_P & 32 & 81.3 & 81.3 & 81.3 & 81.3 & 78.1 & 81.3 & 68.8 & 78.1 & 78.1 & 43.8 & 81.3 & 81.3 & & \\
\hline L Eve_P & 64 & 95.3 & 98.4 & 95.3 & 96.9 & 98.4 & 98.4 & 95.3 & 98.4 & 98.4 & 79.7 & & 95.3 & 98.4 & 98.4 \\
\hline L GOSH_P & 106 & 89.6 & 94.3 & 89.6 & 93.4 & 96.2 & 85.8 & 86.8 & 94.3 & 91.5 & & 84.9 & 77.4 & 94.3 & 94.3 \\
\hline Leeds_P & 50 & 98.0 & 98.0 & 98.0 & 98.0 & 98.0 & 98.0 & 26.0 & 98.0 & 98.0 & 92.0 & 96.0 & 98.0 & 98.0 & 96.0 \\
\hline Livpl_P & 26 & 57.7 & 50.0 & 50.0 & 57.7 & 57.7 & 57.7 & 57.7 & 53.8 & 42.3 & 42.3 & 57.7 & 57.7 & 0.0 & 0.0 \\
\hline Manch_P & 30 & 33.3 & 33.3 & 33.3 & 33.3 & 33.3 & 33.3 & 10.0 & 33.3 & 33.3 & 33.3 & 33.3 & 33.3 & 33.3 & 33.3 \\
\hline Newc_P & 22 & 22.7 & 22.7 & 22.7 & 22.7 & 22.7 & 22.7 & 18.2 & 22.7 & 22.7 & 18.2 & 18.2 & 22.7 & 0.0 & 0.0 \\
\hline Nottm_P & 55 & 89.1 & 92.7 & 89.1 & 94.5 & 92.7 & 94.5 & 80.0 & 94.5 & 94.5 & 36.4 & 94.5 & 89.1 & 89.1 & 87.3 \\
\hline Soton_P & 8 & 87.5 & 100.0 & 87.5 & 62.5 & 25.0 & 87.5 & 12.5 & 25.0 & 25.0 & 0.0 & 0.0 & 75.0 & 25.0 & 12.5 \\
\hline UK & 519 & 84.2 & 85.9 & 83.8 & 85.4 & 85.4 & 84.6 & 61.3 & 82.5 & 80.7 & 46.4 & 80.0 & 81.5 & 71.7 & 71.1 \\
\hline
\end{tabular}

Blank cells represent data items that could not be sent by centres due to technical reasons 
Table 11.4. Percentage data completeness for dialysis patients by centre for each variable and total number of patients per centre in 2010

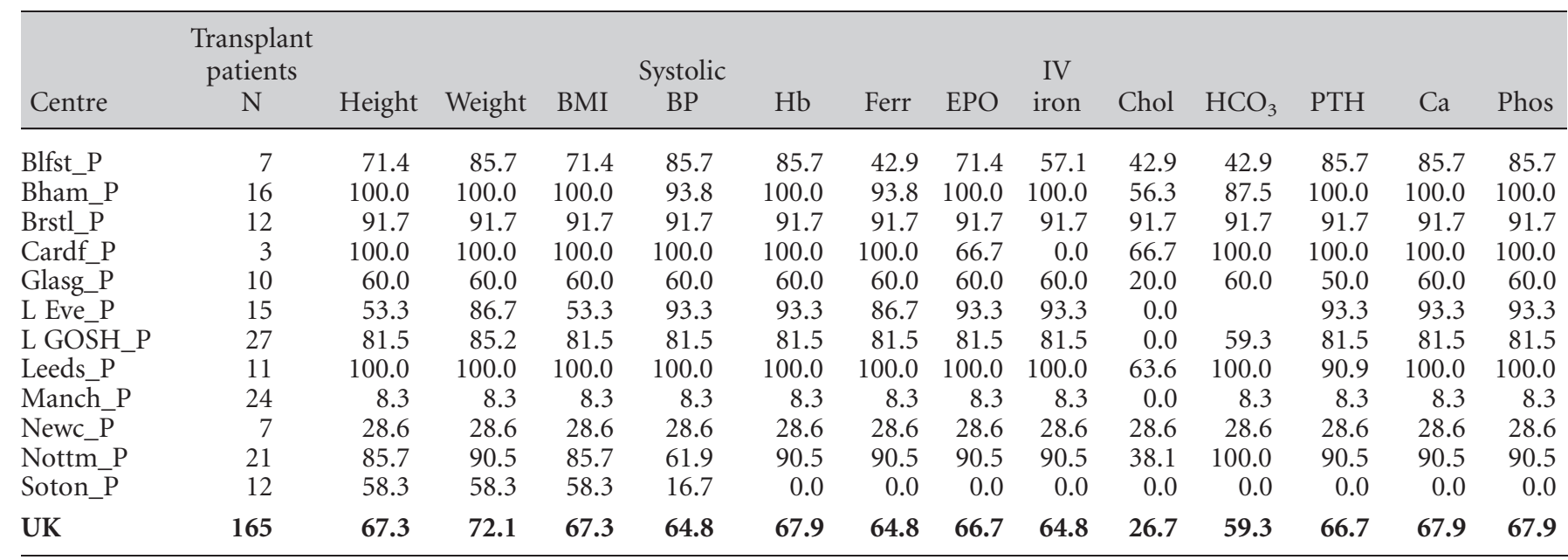

Blank cells represent data items that could not be sent by centres due to technical reasons

Liverpool is not shown in this table as they did not have any patients under 16 years on dialysis in 2010

Table 11.5. Percentage data completeness for each variable for each transplant patient per year from 2000-2010

\begin{tabular}{|c|c|c|c|c|c|c|c|c|}
\hline Centre & $\begin{array}{c}\text { Transplant patient } \\
\text { years }\end{array}$ & Height & Weight & $\begin{array}{c}\text { Systolic } \\
\text { BP }\end{array}$ & $\mathrm{Hb}$ & eGFR & Creatinine & Ferritin \\
\hline Blfst_P & 102 & 94.1 & 94.1 & 95.1 & 100.0 & 94.1 & 100.0 & 35.3 \\
\hline Brstl_P & 286 & 96.5 & 98.3 & 95.1 & 96.2 & 93.7 & 96.5 & 24.8 \\
\hline Cardf_P & 145 & 89.7 & 92.4 & 92.4 & 98.6 & 89.7 & 99.3 & 60.7 \\
\hline Glasg_P & 319 & 95.6 & 97.2 & 96.9 & 98.4 & 95.6 & 99.7 & 51.7 \\
\hline Leeds_P & 274 & 93.8 & 94.9 & 94.5 & 94.9 & 92.7 & 97.1 & 15.7 \\
\hline Livpl_P & 230 & 96.1 & 97.8 & 98.7 & 98.7 & 95.7 & 98.7 & 59.1 \\
\hline Manch_P & 457 & 97.2 & 98.9 & 98.0 & 98.7 & 96.9 & 98.9 & 3.5 \\
\hline Newc_P & 170 & 97.1 & 98.2 & 97.6 & 97.6 & 97.1 & 100.0 & 41.2 \\
\hline Nottm_P & 456 & 89.9 & 91.7 & 91.0 & 96.5 & 89.0 & 98.5 & 38.8 \\
\hline Soton_P & 63 & 81.0 & 85.7 & 82.5 & 79.4 & 79.4 & 88.9 & 14.3 \\
\hline
\end{tabular}

Table 11.6. Percentage data completeness for each variable for dialysis patients per centre per year from 2000-2010

\begin{tabular}{|c|c|c|c|c|c|c|c|c|c|}
\hline Centre & $\begin{array}{c}\text { Dialysis patient } \\
\mathrm{N}\end{array}$ & Height & Weight & $\begin{array}{c}\text { Systolic } \\
\text { BP }\end{array}$ & $\mathrm{Hb}$ & PTH & $\mathrm{Ca}$ & Phos & Ferritin \\
\hline Blfst_P & 62 & 91.9 & 98.4 & 98.4 & 100.0 & 87.1 & 91.9 & 91.9 & 66.1 \\
\hline Brstl_ $\bar{P}$ & 123 & 93.5 & 97.6 & 97.6 & 97.6 & 91.9 & 96.7 & 96.7 & 69.1 \\
\hline Cardf_P & 29 & 89.7 & 96.6 & 96.6 & 100.0 & 82.8 & 100.0 & 100.0 & 93.1 \\
\hline Glasg_P & 94 & 86.2 & 96.8 & 95.7 & 98.9 & 85.1 & 95.7 & 97.9 & 87.2 \\
\hline Leeds_P & 124 & 88.7 & 91.1 & 88.7 & 93.5 & 86.3 & 91.9 & 93.5 & 87.1 \\
\hline Livpl_P & 63 & 85.7 & 100.0 & 98.4 & 100.0 & 82.5 & 96.8 & 95.2 & 88.9 \\
\hline Manch_P & 182 & 92.3 & 94.0 & 90.1 & 98.4 & 87.9 & 98.4 & 98.4 & 79.7 \\
\hline Newc_P & 57 & 91.2 & 94.7 & 94.7 & 96.5 & 86.0 & 98.2 & 98.2 & 89.5 \\
\hline Nottm_P & 176 & 67.0 & 76.7 & 61.4 & 97.2 & 83.0 & 98.9 & 98.9 & 74.4 \\
\hline Soton_P & 26 & 88.5 & 96.2 & 76.9 & 73.1 & 69.2 & 73.1 & 73.1 & 57.7 \\
\hline
\end{tabular}



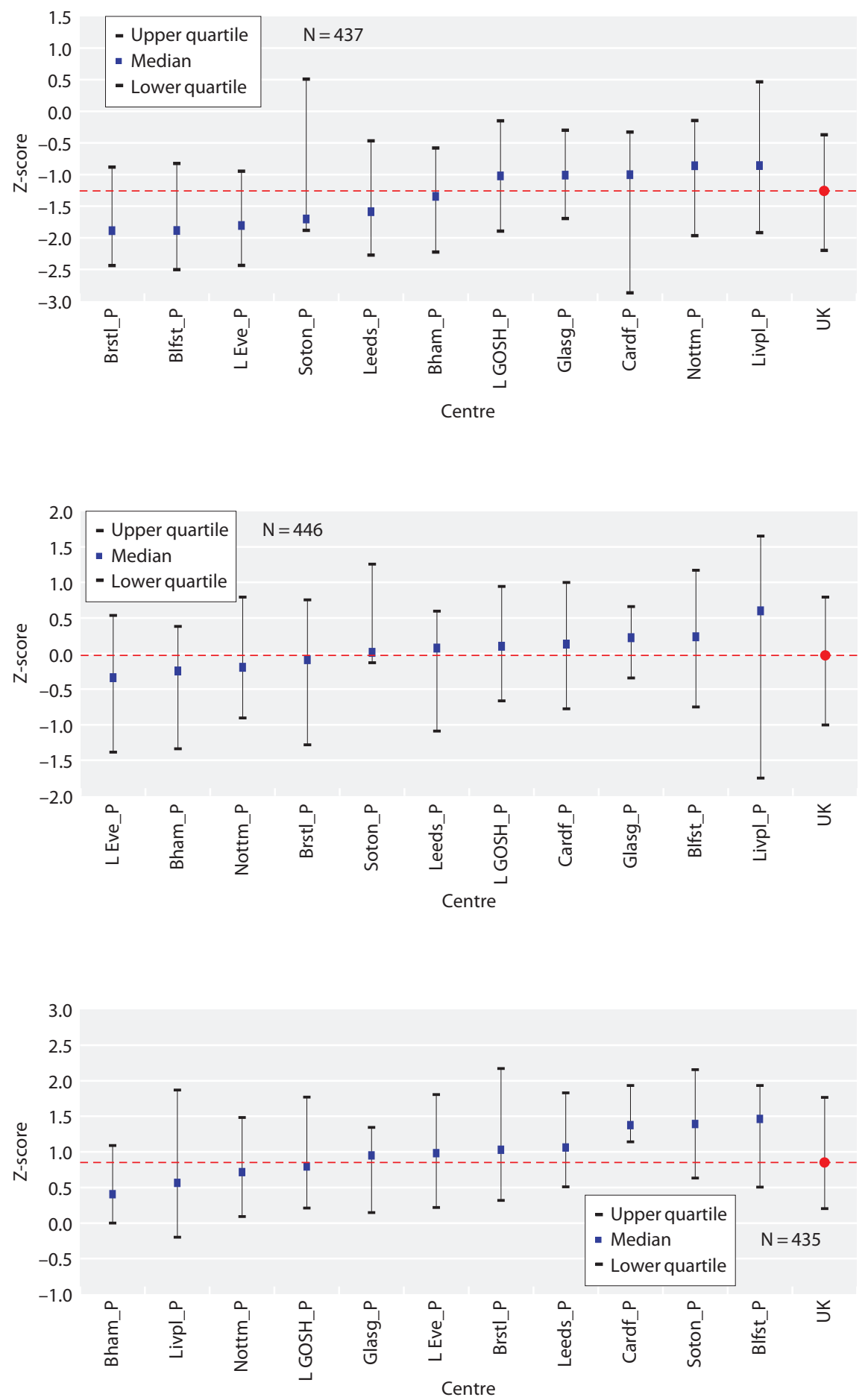

Fig. 11.1. Median height $\mathrm{z}$-scores for transplant patients in 2010

Centres with less than $50 \%$ data completeness were excluded from the centre specific analysis but were included in the UK totals

Fig. 11.2. Median weight $\mathrm{z}$-scores for transplant patients in 2010

Centres with less than $50 \%$ data completeness were excluded from the centre specific analysis but were included in the UK totals

Fig. 11.3. Median BMI z-scores for transplant patients in 2010

Centres with less than $50 \%$ data completeness were excluded from the centre specific analysis but were included in the UK totals replacement therapy than in healthy children (figures $11.8,11.9)$. There was wide inter-centre variation in systolic blood pressure, particularly in dialysis patients in 2010 with a UK median z-score of 0.23 for dialysis patients and 0.38 for transplant patients.
Although children receiving dialysis had a slightly lower median SBP $\mathrm{z}$-score compared to transplant patients, a higher proportion of dialysis patients had SBP above the 90th percentile (table 11.7). For children with a functioning kidney transplant, $78.6 \%$ had a 

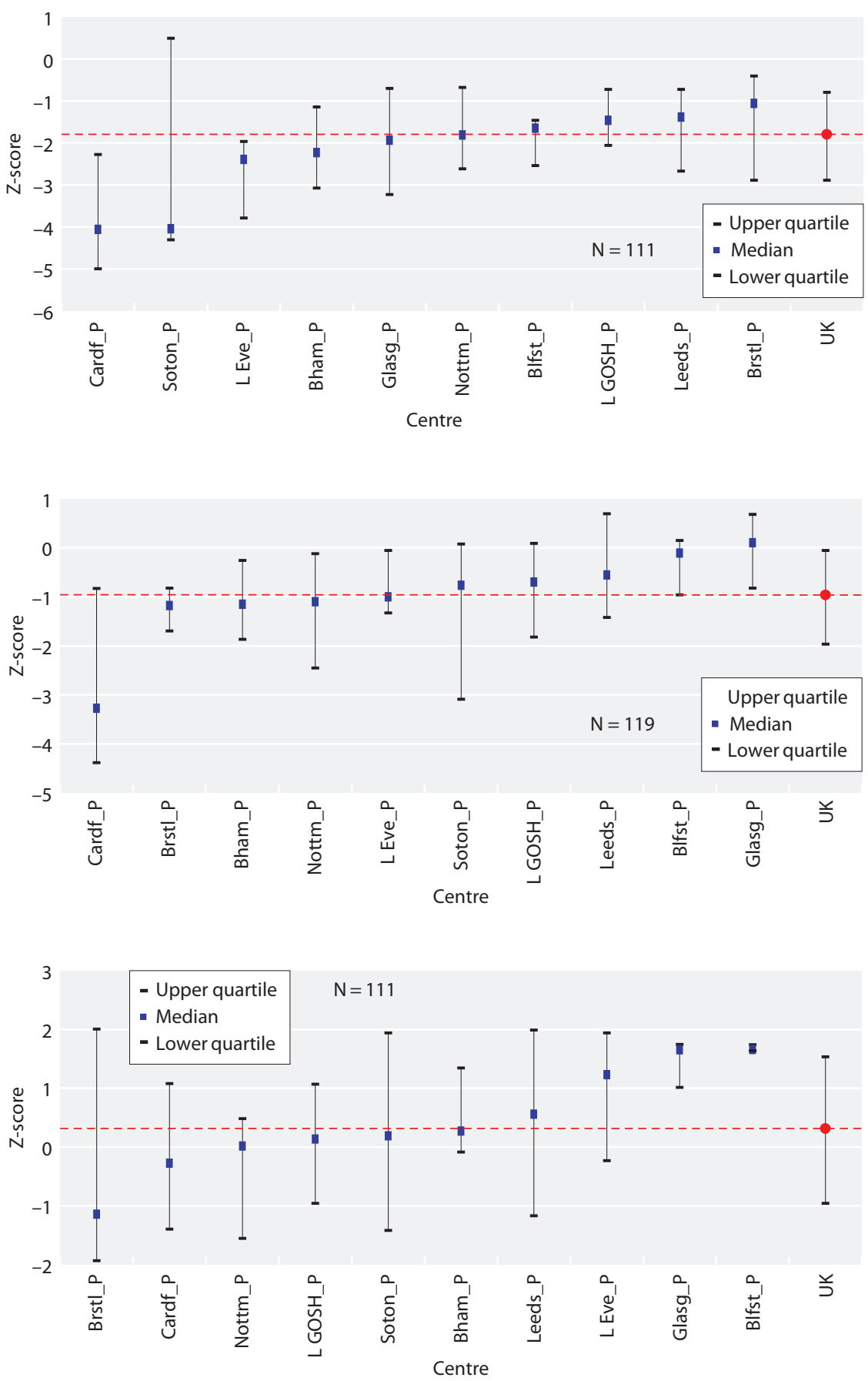

Fig. 11.4. Median height z-scores for dialysis patients in 2010 Centres with less than $50 \%$ data completeness were excluded from the centre specific analysis but were included in the UK totals

Fig. 11.5. Median weight $\mathrm{z}$-scores for dialysis patients in 2010

Centres with less than $50 \%$ data completeness were excluded from the centre specific analysis but were included in the UK totals

Fig. 11.6. Median BMI z-scores for dialysis patients in 2010

Centres with less than $50 \%$ data completeness were excluded from the centre specific analysis but were included in the UK totals systolic BP <90th percentile which was slightly better than last year when $73.2 \%$ of such children achieved the target (table 11.7). In comparison, $71.1 \%$ of children on haemodialysis had a systolic BP $<90$ th percentile whilst $74.2 \%$ of children receiving peritoneal dialysis achieved this (table 11.7). The results for peritoneal dialysis are substantially better than those achieved in the previous year $(51.7 \%)$. When analysing data by age, blood pressure control was slightly worse in the 5-11.99 year age group irrespective of RRT modality.

\section{Haemoglobin}

The analyses in this report continue to show that many children receiving renal replacement therapy are anaemic. Fifty one percent (centre range 35-77\%) of children with a functioning transplant achieved the 

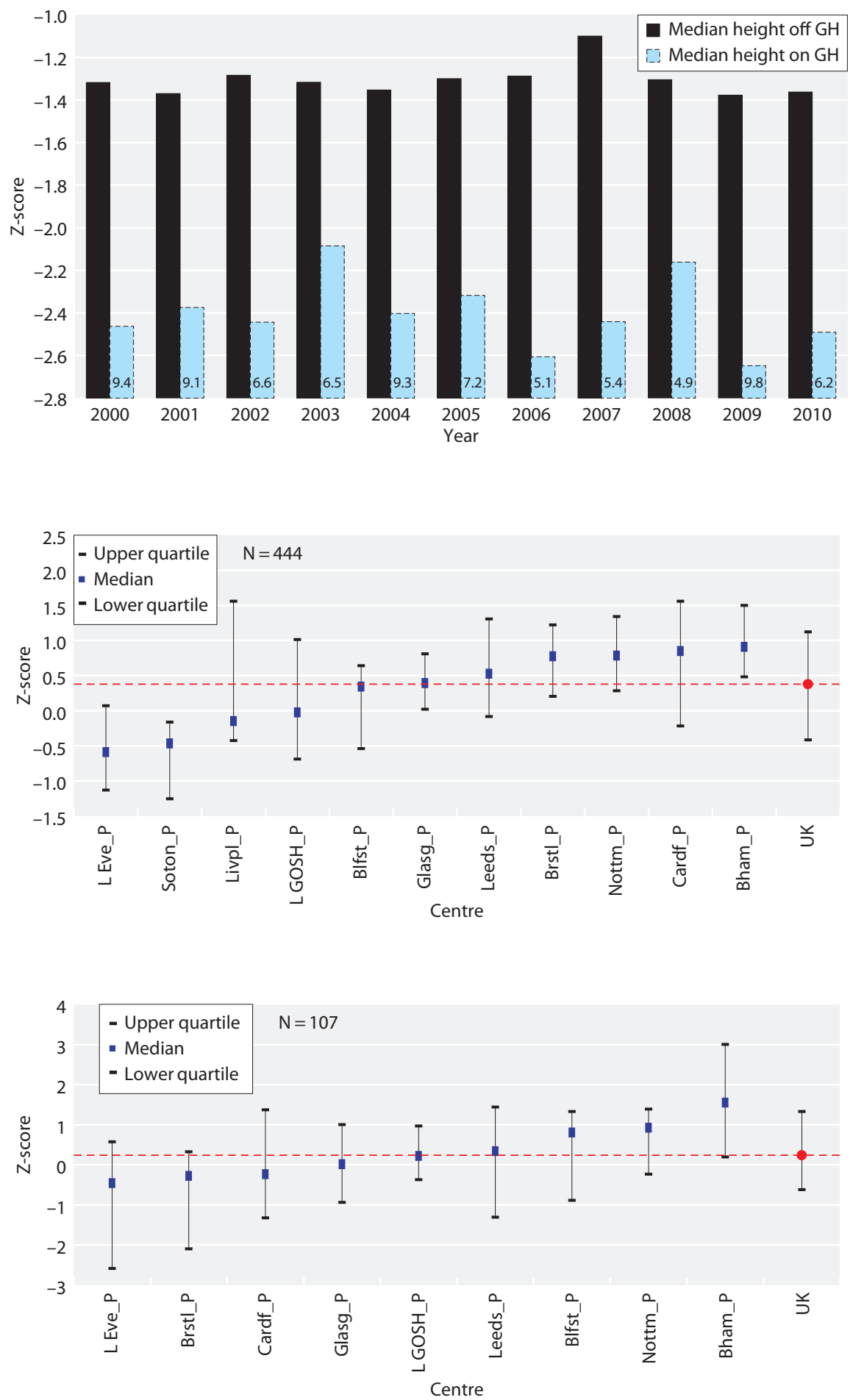

Fig. 11.7. Median height $\mathrm{z}$-scores in paediatric patients receiving RRT from 2000 to 2010 , with the percentage of children using growth hormone each year

Fig. 11.8. Median systolic blood pressure Z-scores for transplant patients in 2010 Centres with less than $50 \%$ data completeness were excluded from the centres specific analysis but were included in the UK totals

Fig. 11.9. Median systolic blood pressure Z-scores for dialysis patients in 2010 Centres with less than $50 \%$ data completeness were excluded from the centres specific analysis but were included in the UK totals haemoglobin standard (table 11.8). This was despite the analysis methodology adjusting the target haemoglobin for children with poor graft function (CKD 3bT or lower) and using the NICE standard for management of anaemia in chronic kidney disease for these patients.

Forty seven percent of haemodialysis patients and $28 \%$ of peritoneal dialysis patients had haemoglobin 
Table 11.7. Percentage of patients achieving the standards for systolic blood pressure in 2010

\begin{tabular}{|c|c|c|c|c|c|c|}
\hline \multirow[b]{2}{*}{ Centre } & \multicolumn{2}{|c|}{ Transplant patients } & \multicolumn{2}{|c|}{ Haemodialysis patients } & \multicolumn{2}{|c|}{ Peritoneal dialysis patients } \\
\hline & $\begin{array}{c}\text { Patients with data } \\
\text { N }\end{array}$ & $\begin{array}{l}\text { Below 90th } \\
\text { percentile }\end{array}$ & $\begin{array}{c}\text { Patients with data } \\
\text { N }\end{array}$ & $\begin{array}{c}\text { Below 90th } \\
\text { percentile }\end{array}$ & $\begin{array}{c}\text { Patients with data } \\
\text { N }\end{array}$ & $\begin{array}{c}\text { Below 90th } \\
\text { percentile }\end{array}$ \\
\hline Blfst_P & 20 & 85.0 & 2 & 50.0 & 4 & 75.0 \\
\hline Bham_P & 54 & 64.8 & 7 & 28.6 & 8 & 62.5 \\
\hline Brstl_P & 33 & 78.8 & 6 & 100.0 & 5 & 80.0 \\
\hline L Eve_P & 62 & 95.2 & 6 & 83.3 & 8 & 75.0 \\
\hline L GOS̄H_P & 100 & 84.0 & 9 & 66.7 & 13 & 92.3 \\
\hline Leeds_P & 49 & 73.5 & 6 & 66.7 & 5 & 60.0 \\
\hline Livpl_P & 15 & 73.3 & $\mathrm{n} / \mathrm{a}$ & $\mathrm{n} / \mathrm{a}$ & $\mathrm{n} / \mathrm{a}$ & $\mathrm{n} / \mathrm{a}$ \\
\hline Nottm_P & 52 & 69.2 & 6 & 83.3 & 7 & 42.9 \\
\hline $5-11.99$ & 186 & 75.3 & 16 & 62.5 & 25 & 64.0 \\
\hline $12-15.99$ & 220 & 81.8 & 15 & 73.3 & 12 & 75.0 \\
\hline
\end{tabular}

${ }^{a}$ Liverpool did not have any dialysis patients under 16 years in 2010

${ }^{\mathrm{b}}$ As Newcastle and Manchester had $<50 \%$ completeness for all groups they have been excluded from centre specific analysis, though included in the UK totals

Blank cells denote categories where data completion is $<50 \%$ complete, and thus not displayed

Table 11.8. Percentage of patients achieving the haemoglobin standard in 2010

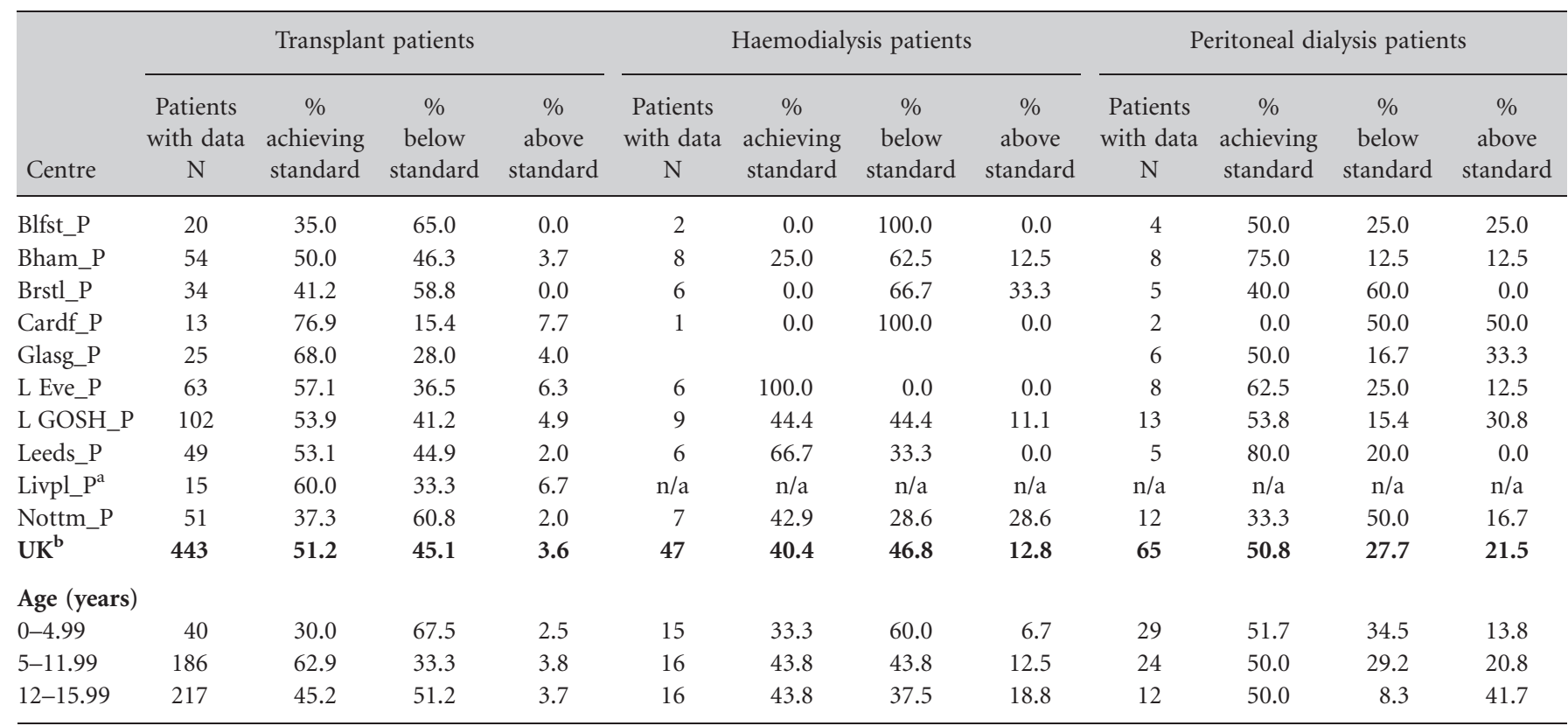

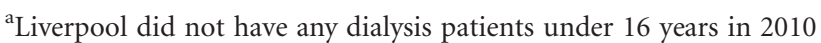

${ }^{\mathrm{b}}$ As Newcastle, Manchester and Southampton had $<50 \%$ completeness for all groups they have been excluded from centre specific analysis, though included in the UK totals

Blank cells denote categories where data completion is $<50 \%$ complete, and thus not displayed 


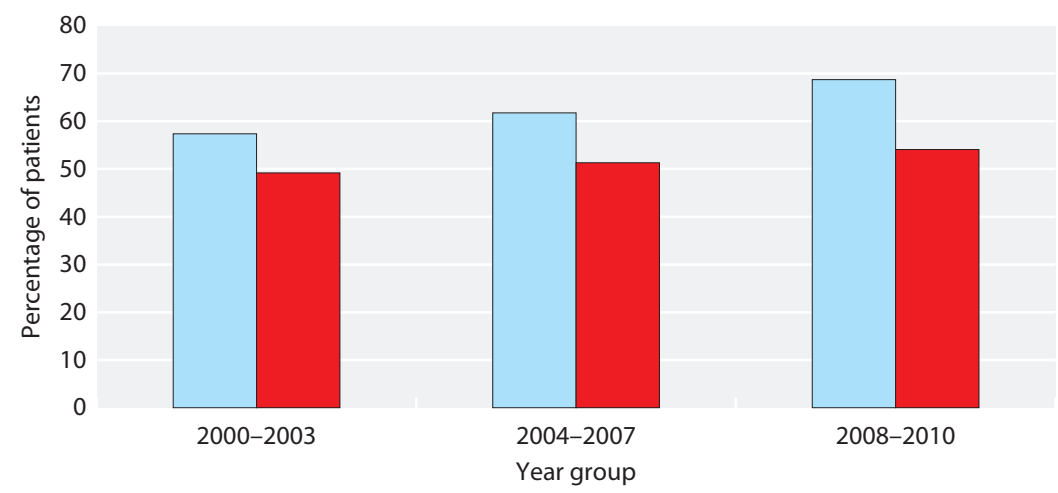

Fig. 11.10. The percentage of paediatric dialysis patients achieving the treatment standards for haemoglobin from 2000-2010 levels below the standard. A significant percentage of children also had haemoglobin concentrations above the recommended standard (13\% for HD and $28 \%$ for $\mathrm{PD})$. The importance of this in the paediatric population, with a very different spectrum of comorbidity from adults, is not known. Analysis by age showed that the proportion of children with a haemoglobin below the standard was greatest for the under 5 years age group irrespective of RRT modality. As for the proportion of children achieving above the recommended haemoglobin standard this appears to increase with age in children on haemodialysis and peritoneal dialysis (table 11.8).

Figure 11.10 shows that the percentage of patients achieving the treatment standards for haemoglobin has gradually increased over the last decade, more noticeably in dialysis patients. In the dialysis group the percentage of patients achieving treatment standards for ferritin has also increased with time with a similar rise noted in those with a functioning transplant. For those with a $\mathrm{Hb}$ below the recommended range, the percentage of

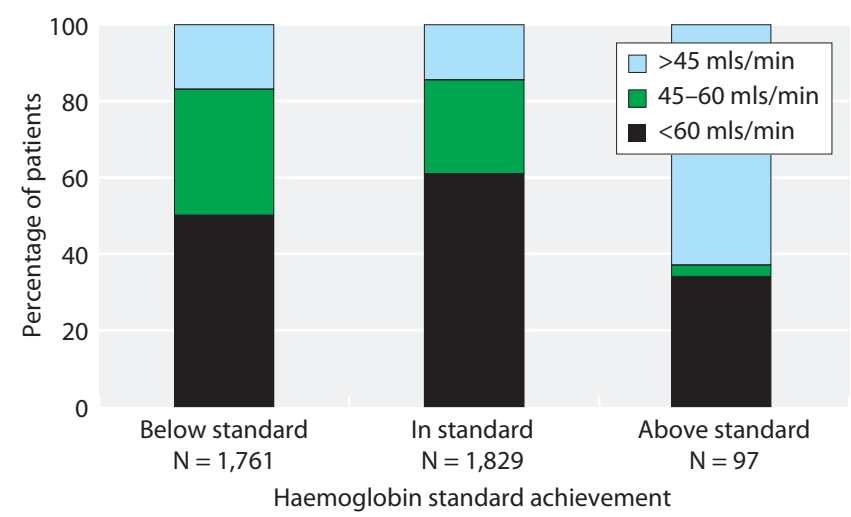

Fig. 11.11. The achievement of haemoglobin treatment standards in paediatric transplant patients, by the level of graft function This figures combines all data from 2000-2010 patients achieving a ferritin within the target range has also increased over the last decade.

The attainment of the haemoglobin standard in transplant patients was assessed for different levels of graft function (figure 11.11) and with the use of MMF as immunosuppressant therapy (figure 11.12). Figure 11.11 demonstrates that haemoglobin standard attainment was marginally worse for patients with transplant dysfunction $(17 \%$ of patients with $\mathrm{Hb}$ below the standard also had an eGFR $<45$ whilst only $14.5 \%$ of patients with a $\mathrm{Hb}$ within the standard had an eGFR $<45)$. As for the impact of MMF, figure 11.12 shows that patients using MMF as immunosuppressant therapy were more likely to have haemoglobin concentrations below the standard, which was statistically significant $\mathrm{p}<0.0001$.

Regarding the use of Erythropoietin and IV iron, figure 11.13 shows that there has been a reduction in the use of both agents in the last 2 years. More patients are on EPO than IV iron in both the transplant and dialysis groups.

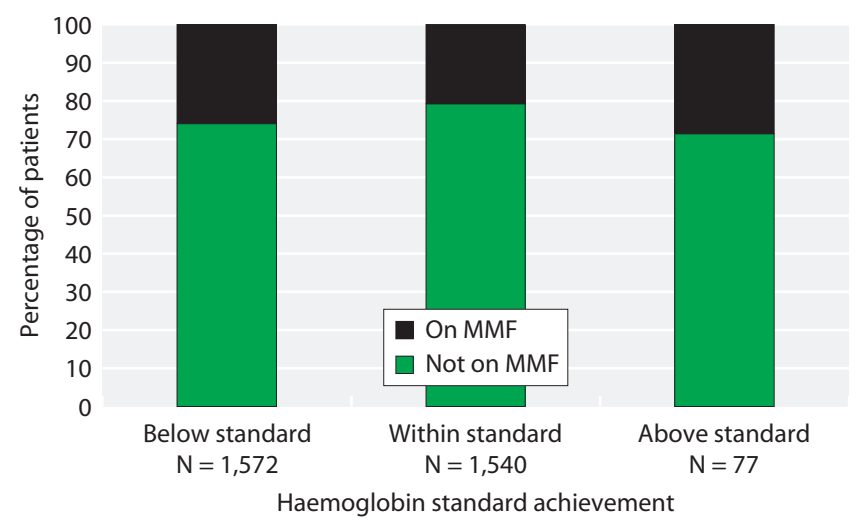

Fig. 11.12. The achievement of haemoglobin treatment standards in paediatric transplant patients, by use of MMF This figure combines all data from 2000-2010 


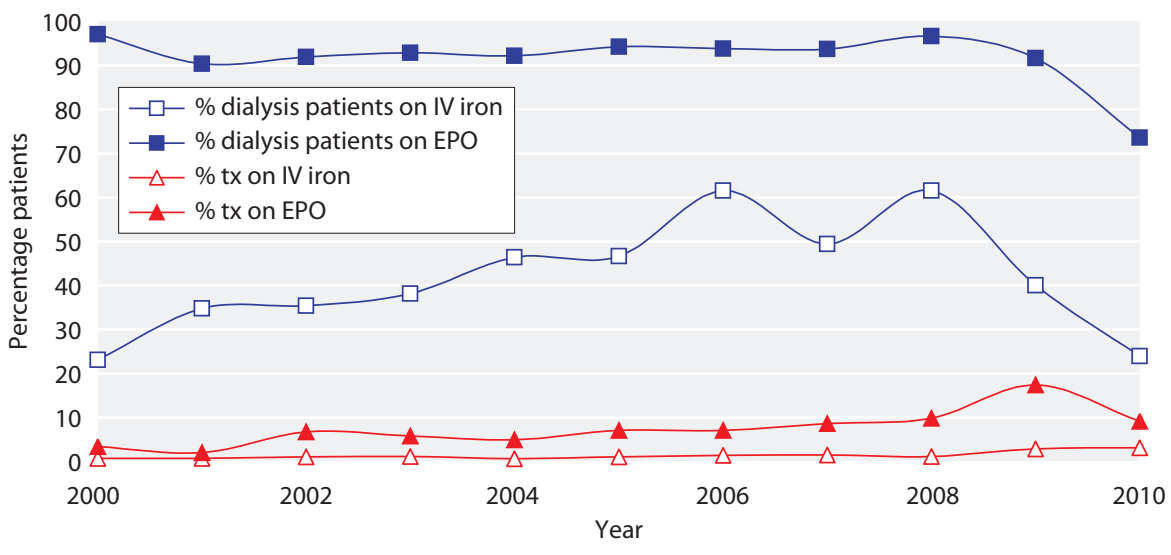

Fig. 11.13. The use of erythropoietin and IV iron in paediatric patients between 2000 and 2010 by treatment modality

\section{Phosphate, calcium and PTH}

In 2010 in the UK as a whole, 51\% of haemodialysis patients and $74 \%$ of peritoneal dialysis patients had a phosphate within the target range (table 11.9). The achievement of the standard for calcium was better with $72 \%$ of children on haemodialysis and $82 \%$ of children on peritoneal dialysis having a calcium level within the target range (table 11.10). As for PTH, 31\% of children on HD and $48 \%$ on PD had a PTH within the target range with wide inter-centre variation (table 11.11). In comparison, $77 \%$ of patients with a functioning transplant achieved a PTH within the target range. Caution should be exercised in the interpretation of these analyses as it was not always possible to identify which units were used to measure $\mathrm{PTH}$, for instance if bloods were taken at different laboratories and also some variation exists between the different PTH assays available. There were no significant age related differences seen.

\section{Discussion}

Whilst the move to electronic reporting with multiple data submissions per annum remains incomplete,

Table 11.9. Achievement of the phosphate standard in dialysis patients in 2010

\begin{tabular}{|c|c|c|c|c|c|c|c|c|}
\hline \multirow[b]{2}{*}{ Centre } & \multicolumn{4}{|c|}{ Haemodialysis } & \multicolumn{4}{|c|}{ Peritoneal dialysis } \\
\hline & $\begin{array}{l}\text { Patients with data } \\
\text { N }\end{array}$ & $\begin{array}{l}\text { \% within } \\
\text { standard }\end{array}$ & $\begin{array}{l}\% \text { below } \\
\text { standard }\end{array}$ & $\begin{array}{l}\% \text { above } \\
\text { standard }\end{array}$ & $\begin{array}{c}\text { Patients with data } \\
\text { N }\end{array}$ & $\begin{array}{l}\text { \% within } \\
\text { standard }\end{array}$ & $\begin{array}{l}\% \text { below } \\
\text { standard }\end{array}$ & $\begin{array}{l}\% \text { above } \\
\text { standard }\end{array}$ \\
\hline Blfst_P & 2 & 50.0 & 0.0 & 50.0 & 4 & 75.0 & 25.0 & 0.0 \\
\hline Bham_P & 8 & 62.5 & 0.0 & 37.5 & 8 & 75.0 & 12.5 & 12.5 \\
\hline Brstl_P & 6 & 66.7 & 0.0 & 33.3 & 5 & 60.0 & 0.0 & 40.0 \\
\hline Cardf_P & 1 & 0.0 & 0.0 & 100.0 & 2 & 100.0 & 0.0 & 0.0 \\
\hline Glasg_P & & & & & 6 & 83.3 & 0.0 & 16.7 \\
\hline L Eve_P & 6 & 16.7 & 33.3 & 50.0 & 8 & 75.0 & 12.5 & 12.5 \\
\hline L GOSH_P & 9 & 66.7 & 0.0 & 33.3 & 13 & 92.3 & 0.0 & 7.7 \\
\hline Leeds_P & 6 & 50.0 & 0.0 & 50.0 & 5 & 40.0 & 20.0 & 40.0 \\
\hline Nottm_P & 7 & 42.9 & 0.0 & 57.1 & 12 & 66.7 & 0.0 & 33.3 \\
\hline $\mathbf{U K}^{\mathrm{a}}$ & 47 & 51.1 & 4.3 & 44.7 & 65 & 73.8 & 7.7 & 18.5 \\
\hline \multicolumn{9}{|l|}{ Age (years) } \\
\hline $0-4.99$ & 15 & 73.3 & 6.7 & 20.0 & 29 & 75.9 & 3.4 & 20.7 \\
\hline $5-11.99$ & 16 & 43.8 & 6.3 & 50.0 & 24 & 70.8 & 12.5 & 16.7 \\
\hline $12-15.99$ & 16 & 37.5 & 0.0 & 62.5 & 12 & 75.0 & 8.3 & 16.7 \\
\hline
\end{tabular}

aAs Newcastle, Manchester and Southampton had $<50 \%$ completeness for all groups they have been excluded from centre specific analysis, though included in the UK totals

Liverpool did not have any dialysis patients under 16 years in 2010

Blank cells denote categories where data completion is $<50 \%$ complete, and thus not displayed 
Table 11.10. Achievement of the adjusted calcium standard in dialysis patients in 2010

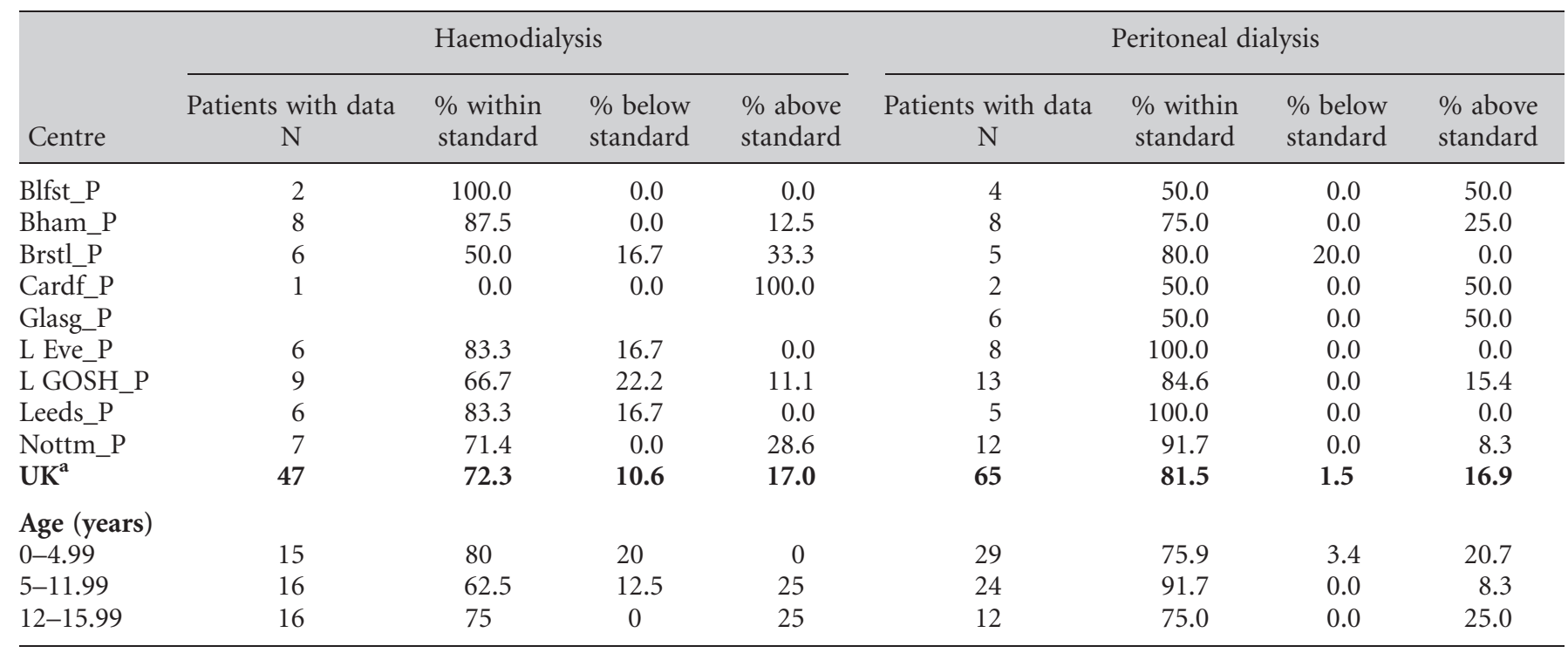

${ }^{a}$ As Newcastle, Manchester and Southampton had $<50 \%$ completeness for all groups they have been excluded from centre specific analysis, though included in the UK totals

Liverpool did not have any dialysis patients under 16 years in 2010

Blank cells denote categories where data completion is $<50 \%$ complete, and thus not displayed

interpretation of annual census data with regard to haematological, biochemical and blood pressure parameters, needs to be made with caution. Technical difficulties and lack of resources has meant that the proportion of patients from whom anthropometric and laboratory data were available for analysis was smaller this year than in previous reports. The most significant contribution to this difficulty related to the move of the

Table 11.11. Percentage of patients achieving the PTH standard 2010

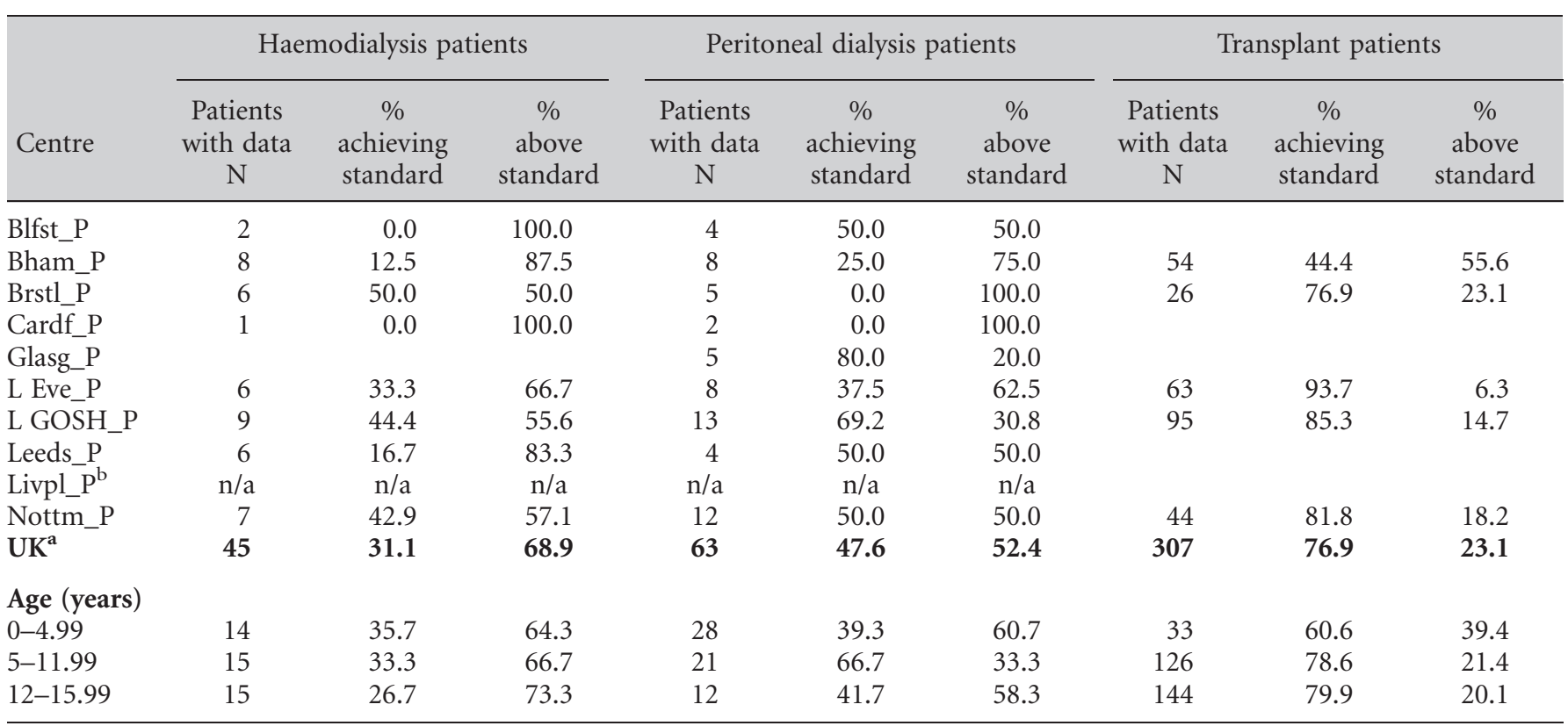

${ }^{a}$ As Newcastle, Manchester and Southampton had $<50 \%$ completeness for all groups they have been excluded from centre specific analysis, though included in the UK totals

${ }^{b}$ Liverpool did not have any dialysis patients under 16 years in 2010

Blank cells denote categories where data completion is $<50 \%$ complete, and thus not displayed 
Manchester paediatric nephrology service to a new centre with reduced administrative support and access to a Renal IT system that is only now becoming live. Over the whole UK there were only a small number of children on any specific modality of dialysis at one time point and within the course of a year, parameters such as calcium, phosphate and PTH may vary greatly within any individual. The ability to look at annual average values for different parameters in the future will be a great advance. That said a number of recurring themes are evident again this year.

\section{Anthropometry}

As in previous reports the paediatric RRT population was shorter than the UK average, with children on dialysis having a greater height deficit than those who have a transplant. The data shown this year indicate that amongst children on renal replacement therapy, with a height two standard deviations below the mean, approximately one quarter are treated with growth hormone, with the percentage treated amongst transplanted children being even lower at 10\%. Chromosomal anomalies and syndromic diagnoses may cause growth restriction which is not amenable to treatment with growth hormone but it is unlikely that this accounts for this low percentage as the numbers of children reported to have chromosomal anomalies and syndromic diagnoses are small (see chapter 5 Demography of the UK Paediatric RRT Population). The indication for the licence for growth hormone treatment in renal disease is chronic kidney disease including dialysis. Initial studies in transplant patients suggested that growth hormone treatment might be associated with an increased risk of rejection [6] and although this has never been shown conclusively, it may explain the pattern of use of growth hormone in this patient group. An increasing number of patients are on steroid free immunosuppression regimens and it would be useful in future analyses to look at this sub-group to see if this is beneficial for growth.

In 2010, children with a transplant had a normal weight for age, but as they were short their BMI was above the UK average with a median $\mathrm{z}$-score of 0.80 . The dialysis patients had lower weights and heights than an age-related population, with height being more affected than weight, their median BMI z-score was 0.30 . More detailed analysis of growth and nutritional state by age group may be informative although without details of pubertal development the data will need to be interpreted with caution.

\section{Blood pressure}

Achieving targets for blood pressure remained challenging, although overall there has been an improvement in the number of patients achieving the BP audit standard. There is inter-centre variation with some centres achieving excellent results. As these data represent one reading per year, they need to be interpreted with caution and there are, of course, many influences on the recorded blood pressure. Differences in measurement technique may be an important factor. For children with a functioning kidney transplant, $78.6 \%$ had a systolic $\mathrm{BP}<90$ th percentile which was slightly better than last year when $73.2 \%$ of such children achieved the target (table 11.7). There was no improvement in the number meeting the standard in the haemodialysis population, $71.1 \%$ this year versus $75.6 \%$ last year, however an improvement was seen in the peritoneal dialysis population from $51.7 \%$ last year to $74.2 \%$ this year. This year the data have been analysed by age. For all treatment modalities, results in the 5-11.99 year age group were lower than younger or older children. This was unexpected and needs further analysis to understand why this should be.

There is increasing literature that suggests that a $\mathrm{BP}$ closer to the 50th centile may be beneficial [7] and although currently the evidence is limited to pre-dialysis CKD patients the standard for future years may change. Data on the use of hypertensives are collected and may be analysed in future reports. The use of lower target blood pressure and/or the use of particular subclasses of antihypertensives such as ACE/ARBs together with the presence or absence of LVH would be an appropriate topic for future audit and research.

\section{Anaemia}

As with previous reports the management of anaemia remained imperfect. However in 2010, more dialysis patients were achieving a $\mathrm{Hb}$ within the recommended range as well as a ferritin within the target range, although there is still scope for improvement. To get further information as to why many patients were not achieving standards, analyses focussing on the use of IV iron and ESA as well as treatment modality in anaemic patients would be helpful, but improved reporting of ferritin would be needed to enable this. It is noticeable that very young children are less likely to reach the standard and this may be due to a reluctance to use ESAs subcutaneously in this group. With all treatment modalities a small percentage of patients had a $\mathrm{Hb}$ above the recommended level, although this has reduced when compared with the 2008 and 2009 data. Trials in adults, with both pre-dialysis

Nephron Clin Pract 2012;120(suppl 1):c219-c232 
and dialysis dependent $\mathrm{CKD}$, comparing effects of treatment of anaemia to different targets, have reported higher rates of adverse events in subjects in whom higher targeted $\mathrm{Hb}$ levels were sought $[8,9]$. The significance of this in the paediatric population is not known.

More patients in both the dialysis and transplant groups were on ESAs than IV iron. It could be argued that more patients should be treated with IV iron before commencing ESAs. The data for the dialysis patients show that many were not achieving ferritin levels within the audit standards. The trends over time showed a recent reduction in the use of both IV iron and ESAs. These changes may reflect the publication in 2006 of NICE guidance for the management of anaemia in CKD which for the first time gave an upper limit for the $\mathrm{Hb}$ target followed by the publication of the 2008 Registry report which showed achievement of these audit standards indicating that there were a significant number of dialysis patients with $\mathrm{Hb}$ above targets [1].

\section{Biochemistry}

Bone disease remained a major problem in children with ERF. The percentage achieving desired targets remained too low. Again, more robust analysis will be possible when annual patient trends rather than isolated values can be reported. The analyses of the achievement of audit standards by modality and age group shows that achievement of calcium and phosphate targets for children on haemodialysis was highest amongst the youngest patients. This probably reflects the reliance of this age group on adults for the provision of their dietary intake and medications. The same trend is not apparent amongst PD patients. The reasons for this are not clear but may relate to the level of residual renal function, further analysis would be needed to confirm this. The achievement of a PTH less than twice the normal range for age was universally poor but the optimal level for PTH in this patient population remains a matter of controversy [10]. The advent of calcimimetics to help control hyperparathyroidism may have a major impact upon the management of renal osteodystrophy in children and future reports will hopefully be able to show whether this is the case.

\section{Summary}

In summary the 2010 report shows that children and young people on renal replacement therapy remained short compared to their peers. Further analyses planned for next year's report may provide more detail but a separate audit project on this important area will be needed to suggest potential interventions. Achievement of recommended targets for blood pressure control and management of anaemia are improving and allow some optimism for continued improvement. Furthermore as more centres move toward electronic reporting, quarterly downloads of data will become possible. This will provide a better picture of what is happening for individual children and allow more robust interpretation of data. This will be particularly helpful for analyses of blood pressure and biochemistry and has the potential to provide very useful feedback to centres on the management of children with RRT, some of whom can be very challenging patients to look after.

Conflicts of interest: none

\section{References}

1 UK Renal Registry 12th Annual Report (December 2009): Chapter 12 Clinical, Haematological and Biochemical Parameters in Patients receiving Renal Replacement Therapy in Paediatric Centres in the UK in 2008: national and centre-specific analyses.

2 Hussain F, Castledine C, Schalkwyk DV, Sinha MD, Lewis MA, Inward C. Nephron Clin Pract 2010;115(suppl 1):c289-c308

- 3 Freeman JV CT, Chinn S et al. Cross sectional stature and weight reference curves for the UK, 1990. Arch Dis Child 1995;73:17-24

- 4 National High Blood Pressure Education Program Working Group on High Blood Pressure in Children and Adolescents. The Fourth Report on the Diagnosis, Evaluation, and Treatment of High Blood Pressure in Children and Adolescents. Pediatrics 2004;114(2):555-576

5 BAPN clinical standards http://www.bapn.org/clinical_standards.html

6 NICE clinical guideline 39. Anaemia management in people with chronic kidney disease. London: National Institute for Health and Clinical Excellence, 2008

7 Tyden G, Berg U, Reinholt F. Acute renal graft rejection after treatment with human growth hormone. Lancet 1990;336:1455-1456

-8 Strict blood-pressure control and progression of renal failure in children, ESCAPE Trial Group, N Engl J Med. 2009 Oct 22;361(17): $1639-1650$

-9 Besarab A, Bolton WK, Browne JK et al. The effects of normal as compared with low hematocrit values in patients with cardiac disease who are receiving hemodialysis and epoetin. New Engl J Med 1998; 339:584-590

10 Singh AK, Szczech L, Tang KL et al. Correction of anemia with epoetin alfa in chronic kidney disease. N Engl J Med 2006;355:2085-2098 